\title{
The impact of heat treatment on the magnetic sensitivity of irradiated by electrons single crystals $n-G e$
}

\author{
S.V.Luniov ${ }^{1}$, A.I.Zimych ${ }^{1}$, M.V.Khvyshchun ${ }^{1}$, V.T.Maslyuk ${ }^{2}$, \\ I.G.Megela ${ }^{2}$ \\ ${ }^{1}$ Lutsk National Technical University, 75 Lvivska Str., 43018 Lutsk, \\ Ukraine \\ ${ }^{2}$ Institute of Electronic Physics, National Academy of Sciences of Ukraine, \\ 21 Universitetska Str., 88017 Uzhghorod, Ukraine
}

Received August 28, 2018

\begin{abstract}
Isothermal annealing of $n-G e$ single crystals irradiated by the electron flux $\Omega=$ $5 \cdot 10^{15} \mathrm{el} / \mathrm{cm}^{2}$, energy of $10 \mathrm{MeV}$, has been investigated. Dependences of Hall voltage on the magnitude of the external magnetic field in the range from 0 to $0.5 \mathrm{~T}$ are obtained by Hall effect measurements. Coefficients of the magnetic sensitivity for irradiated single crystals $n-G e$ before and after annealing at different temperatures were also determined. The abnormal annealing at the temperature of $403 \mathrm{~K}$ has been revealed. Hall constant was being increased during this process, and the maximal magnetic sensitivity was being achieved correspondingly. The given effect is explained by the increasing concentration of radiation defects with deep energy levels (A-centers) owing to the generation of vacancies which are formed in annealing of kernels of regions disordering. Such abnormal annealing can be used as a tool to create highly sensitive Hall sensors by the irradiated $n-G e$.

Keywords: isothermal annealing, radiation defects, magnetic sensitivity, germanium single crystals.
\end{abstract}

Исследован изотермический отжиг облученных монокристаллов $n-G e$ потоком электронов $\Phi=5 \cdot 10^{15}$ эл./ $\mathrm{cm}^{2}$ с энергией $10 \mathrm{MэB.} \mathrm{На} \mathrm{основе} \mathrm{измерений} \mathrm{әффекта} \mathrm{Холла}$ получены зависимости холловского напряжения от величины внешнего магнитного поля в диапазоне от 0 до 0,5 Тл и определены коэффициенты магнитной чувствительности для облученных монокристаллов $n-\mathrm{Ge}$ до и после отжига при различных температурах. При температуре отжига $403 \mathrm{~K}$ обнаружен аномальный отжиг, при котором увеличивалась постоянная Холла и соответственно достигалась максимальная магнитная чувствительность. Данный әффект объясняется ростом концентрации радиационных дефектов с глубокими энергетическими уровнями (А-центров) за счет генерации вакансий, которые образуются при отжиге ядер областей разупорядочения. Такой аномальный отжиг может быть использован как инструмент для создания на основе облученного $n-\mathrm{Ge}$ высокочувствительных датчиков Холла.

Вплив термічної обробки на магнітну чутливість опромінених електронами монокристалів $n-G e$. C.В.Луньов, А.І.Зімич, М.В.Хвищун, В.Т.Маслюк, І.Г.Мегела.

Досліджено ізотермічний відпал опромінених монокристалів $n-G e$ потоком електронів $\Phi=5 \cdot 10^{15}$ ел./ см $^{2}$ з енергією $10 \mathrm{MeB}$. На основі вимірювань ефекту Холла отримано залежності холівської напруги від величини зовнішнього магнітного поля у діапазоні від 0 до 0,5 Тл та визначено коефіцієнти магнітної чутливості для опромінених монокристалів $n-G e$ до і після відпалу при різних температурах. При температурі відпалу 403 К виявлено аномальний відпал, при якому збільшувалася стала Холла $\mathrm{i}$ 
відповідно досягалася максимальна магнітна чутливість. Даний ефект пояснюється зростанням концентрації радіаційних дефектів з глибокими енергетичними рівнями (А-центрів) за рахунок генерації вакансій, які утворюються при відпалі ядер областей розупорядкування. Такий аномальний відпал може бути використаний як інструмент для створення на основі опроміненого $n-G e$ високочутливих датчиків Холла.

\section{Introduction}

Systems of management and control, measuring complexes and devices cannot work without all sorts of converters of physical quantities into electrical signals which are called transducers or sensors [1-4]. At present, the development of semiconductor sensors is one of the most perspective directions in progress of the measuring systems element base. The significant attention is given to the sensors of the magnetic fields. Their nomenclature continually expands that is primarily associated with the development of electronic equipment. Also, measurements of the magnetic fields parameters find their application in both fundamental and applied types of research [5]. For example, measurements of the magnetic fields as well as the parameters of the magneto-conductive environments in the wide frequency range from zero to ultra high values present the essential issue of radio electronics [6]. Problems concerning of the control of the plasma flow in the tokamak systems require particular attention. This control is carried out by the magnetic fields of the appropriate configurations. The magnetic field is regulated by a system of transducers that have high thermal and radiation resistance $[7,8]$. Hall sensors are one of the most common types of the magnetically sensitive items, which are widely used in medicine, engineering, flux detection, geology (in studies of new deposits), in a creation of systems positioning and navigation $[4,6,9-13]$. A wide range of measuring instruments of various types and designs for investigation of the parameters of magnetic fields is represented at the market of magnetic sensor technology nowadays. However, such advanced manufacturers of magnetic sensor devices as "Honeywell", "Asachi Kasei MicroSystems", "Infinlon Technologies", "Micronas", "Melexis N.V." prefer the semiconductor sensors $[14,15]$. Such sensors, with sufficient accuracy for industrial applications, have small dimensions, relatively low price, comfortable in operation.

Intensive development in the field of semiconductor physics and technologies for obtaining these materials contributes to the improvement of properties the existing semiconductor materials, as well as the search and development of new semiconductor materials. The highly sensitive magnetic field sensors by these materials can be created. The elementary semiconductors Si and Ge are relevant to these semiconductors materials, which are used as a raw material for the creation of Hall sensors [6].

As we know [16], physical properties of semiconductors can be significantly modified by the influence of irradiation of high energy particles or quanta of high energies and heat treatment. This allows changing and adjusting them to the required properties purposely. This could serve as the basis of technologies for the creation of the semiconductor devices and sensors with set in advanced properties. Also, research of the radiation defects annealing processes gives the possibility to set the conditions of stable operation of the equipment, which includes elements by the irradiated material. Thus research of the radiation defects annealing processes in single crystals $n-G e$ and their impact on physical properties of single crystals $n-\mathrm{Ge}$ is interesting both from the theoretical and applied points of view.

\section{Experimental results and theoretical calculations}

Influence of irradiation by the electron flux $\Omega=5 \cdot 10^{15} \mathrm{el} . / \mathrm{cm}^{2}$ with the energy of $10 \mathrm{MeV}$ and isothermal annealing on the magnetic sensitivity of single crystals $n-G e$ were investigated in the given work. Results of our previous researchers [17, 18] demonstrate that the point defects (A-centers [19]) and regions of disordering were introduced for the same single crystals $n-G e$ under electron irradiation with mentioned parameters. The author of the work [20] models point defects in $\mathrm{Ge}$ with the same energy spectrum as a complex, which consists of a vacancy, an atom of oxygen and two interstitial atoms of Germanium $\left(\mathrm{VOI}_{2} \mathrm{Ge}\right)$. The isothermal annealing of the irradiated samples $n-G e$ at the temperatures of $403 \mathrm{~K}, 433 \mathrm{~K}, 448 \mathrm{~K}$ and the measurements of temperature dependencies of the Hall constant were carried out to study the influence of heat treatment on the magnetic sensitivity of the irradiated single crystals $n-G e$. We've also obtained dependences 


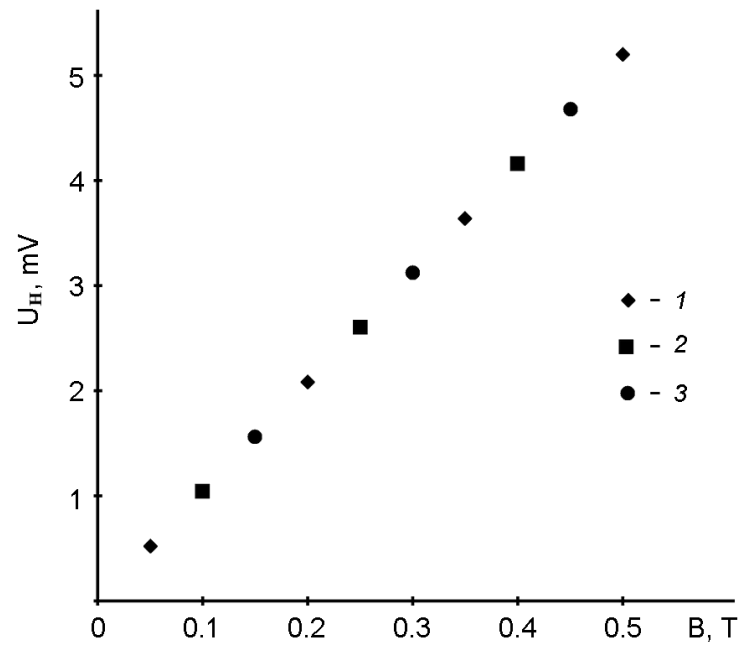

Fig. 1. Dependences of Hall voltage $U_{H}=$ $f(B)$ for the unirradiated single crystals $n-\mathrm{Ge}$ at different temperatures T, T: $1-200$; $2-250 ; 3-300$.

of Hall voltage $U_{H}$ from the induction of magnetic field $B$ in the range from 0 to $0,5 \mathrm{~T}$ for non-irradiated and irradiated samples before and after annealing (Fig. 1 and Fig. 2). When the direction of the current and magnetic field are mutually perpendicular, then by [21] Hall voltage $U_{H}$ can be written as follows:

$$
U_{H}=\frac{R_{H} I B}{d},
$$

where $R_{H}$ is the Hall constant, $I$ is the force of current, which flows through the sample, $B$ is the induction of magnetic field, $d$ is the thickness of sample in the direction of magnetic field. The magnetic sensitivity $\beta$ is one of the base characteristics of Hall sensors $[6,14,15]$ :

$$
\beta=\frac{\partial U_{H}}{\partial B}
$$

If $R_{H}$ does not depend on the magnetic field, then the expression (2) can be written as:

$$
\beta=\frac{U_{H}}{B}=\frac{R_{H} I}{d}
$$

Since the current $I$ and thickness of the sample $d$ can be defined, (for our case $I=$ $1 \mathrm{~mA}, d=0.9 \mathrm{~mm}$ ), the magnetic sensitivity can be determined by the value of Hall constant $R_{H}$. The last one in its turn depends on the concentration of charge carriers and mechanisms of their scattering [21, 22].

For the non-irradiated single crystals $n-\mathrm{Ge}$, doped by the impurity Sb with a concentration $N_{d}=5 \cdot 10^{14} \mathrm{~cm}^{-3}$, the magnetic sensitivity of $\beta=10 \mathrm{mV} / \mathrm{T}$ does not depend on the temperature (Fig. 1) because the shallow donors of $\mathrm{Sb}$ are fully ionized. Under such conditions n-Ge concedes significantly to other materials (which are used in the sensitive elements of Hall sensors) by a value of the magnetic sensitivity [6]. As Hall constant $R_{H}$ is inversely proportional to the concentration of electrons in the conduction band [21, 22] then, by (3), at the decrease of the extent of doping of semiconductors their sensitivity to the magnetic field could be increased correspondingly. However, the control of impurities is one of the problems of the production, for example, of the exceptionally pure germanium single crystals. Their content can be controlled only at the level of sensitivity of modern analytical instruments [23]. Dependences of Hall voltage from the induction of magnetic field before and after iso-
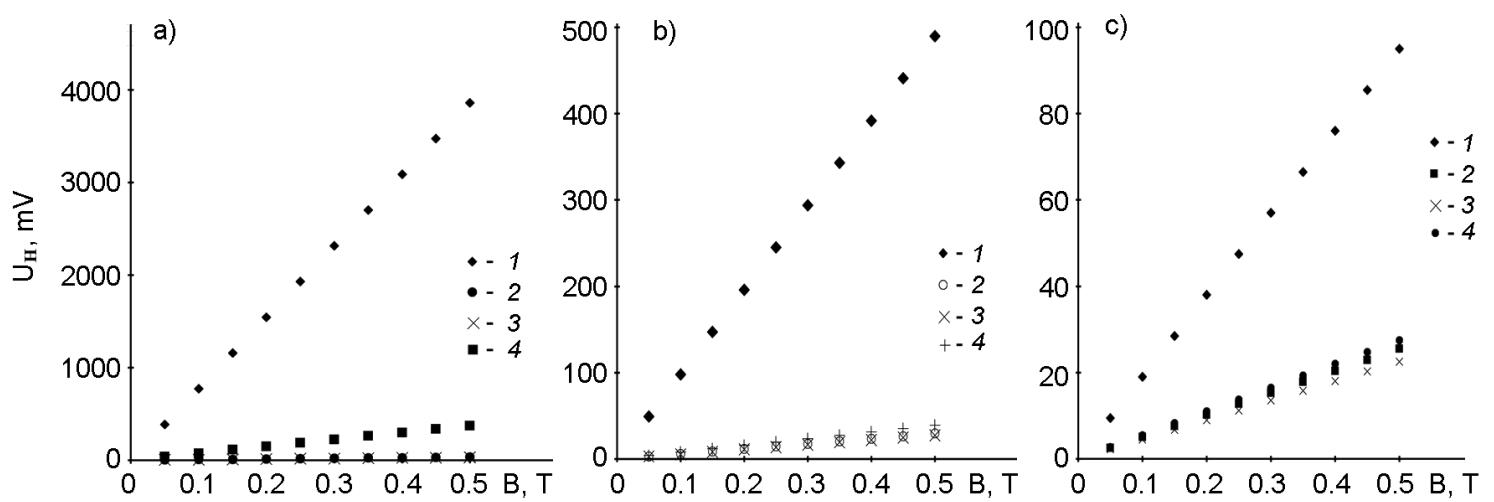

Fig. 2. Dependences of Hall voltage $U_{H}=f(B)$ at $T=200 \mathrm{~K}(\mathrm{a}), T=250 \mathrm{~K}$ (b) and $T=300 \mathrm{~K}$ (c) for the irradiated single crystals $n-G e$ after the heat treatment within $1 \mathrm{~h}$ for different temperatures of annealing $I_{a n}, \mathrm{~K}: 1-403,2-433,3-448,4-$ unannealed sample. 


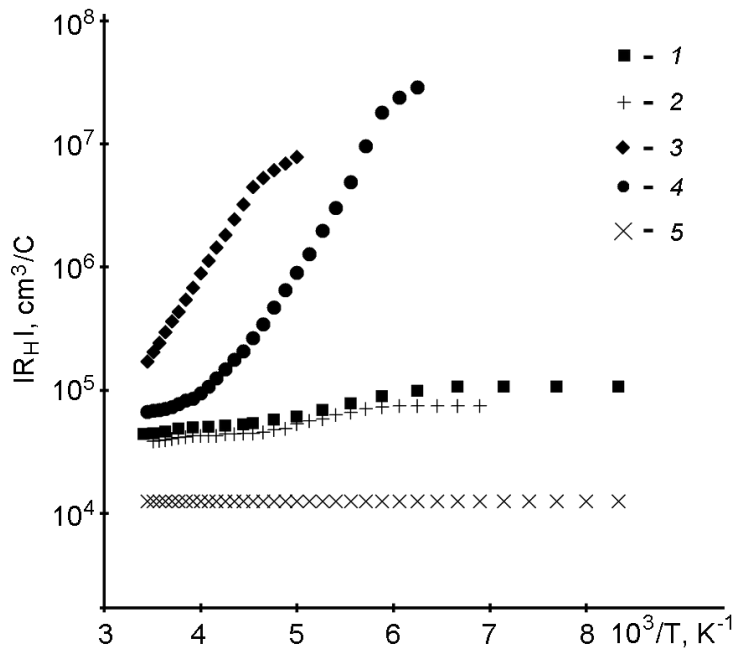

Fig. 3. Temperature dependences of Hall constant $\lg \left(1 R_{H} l\right)=f\left(10^{3} / T\right)$ for the irradiated single crystals $n-G e$ after the heat treatment within $1 \mathrm{~h}$ for different temperatures of annealing $T_{a n}$, K: $1-433 ; 2-448 ; 3-403$; 4 - unannealed sample; 5 - unirradiated sample.

thermal annealing within $1 \mathrm{~h}$ for single crystals $n-G e$ at different temperatures are presented in Fig. 2. All dependences $U_{H}=$ $f(B)$ are linear by these figures. The facts indicate about the minor role of the magnetoresistance. According to the works [24, 25 ], this effect can occur for single crystals of germanium with complexes that hold oxygen only at larger values of magnetic fields. Heat treatment of the irradiated samples within one hour at a temperature of $433 \mathrm{~K}$ (curve 2, Fig. 2) and a temperature of $448 \mathrm{~K}$ (curve 3, Fig. 2) led to a reduction of the magnetic sensitivity. Such behavior differs in comparison with the irradiated (non-annealed) samples (curve 4, Fig. 2). Abnormal growth of magnetic sensitivity in the annealed samples in comparison with the non-annealed was revealed after the isothermal annealing over a period of one hour at a temperature of $403 \mathrm{~K}$ (curves 1, Fig. 2).

The measurements of temperature dependencies of Hall constant for the annealed samples were conducted for a more detailed study of mechanism of the isothermal annealing and its influence on the magnetic sensitivity of the irradiated $n-G e$ single crystals. The results of measurements of the temperature dependences of Hall constant after isothermal annealing over a period of one hour at the temperatures of $403 \mathrm{~K}$, $433 \mathrm{~K}$ and $448 \mathrm{~K}$ are presented at Fig. 3 .

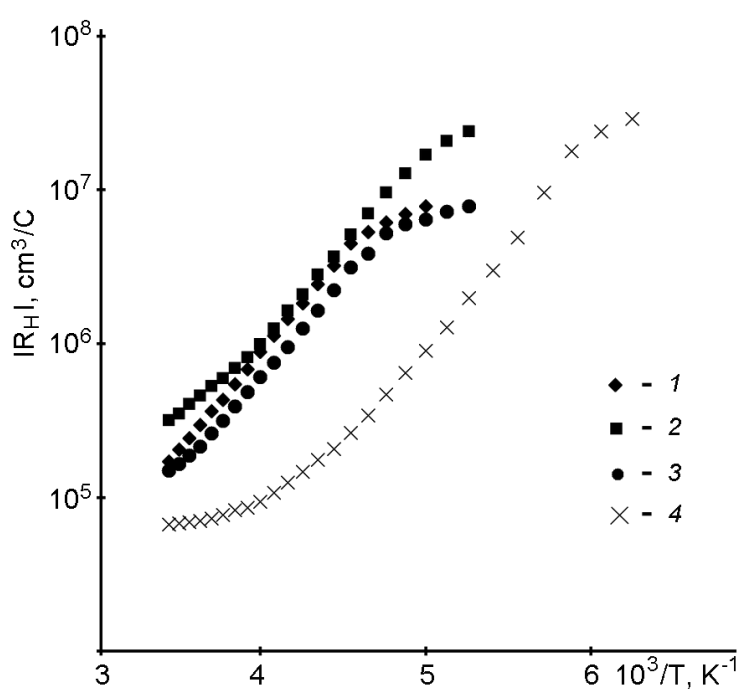

Fig. 4. Temperature dependences of Hall constant $\lg \left(1 R_{H} l\right)=f\left(10^{3} / T\right)$ for the irradiated single crystals $n-G e$ at temperature of the isothermal annealing $T_{a n}=403 \mathrm{~K}$, for different times of annealing $t_{a n}, \mathrm{~h}: 1-1 ; 2-3$; $3-5 ; 4-0$.

As we can see from Fig. 3, the value of Hall constant increased at a temperature of annealing $403 \mathrm{~K}$ (curve 3 ) in comparison with the irradiated (non-annealed) samples (curve 4). The increase of the annealing time to 3 hours at the temperature of $403 \mathrm{~K}$ leads to the growth of Hall constant (curve 2, Fig. 4) and magnetic sensitivity (curve 3, Fig. 5). Further annealing to 5 hours leads to the decrease of Hall constant (curve 3, Fig. 4) and magnetic sensitivity (curve 1, Fig. 5).

We also determined the parameters of radiation defects for the annealed samples because of the change of Hall constant $R_{H}$ after annealing of the irradiated single crystals $n-G e$. It can be caused by both a change in concentration of the existing defects (A-centers, regions of disordering) and the emergence of new complexes with another energy spectrum [26, 27].

Let the equilibrium concentration of radiation defects after the annealing in $n-G e$ constituted $N$ and for each such defect corresponds of $L$ acceptor levels. Then the following equation of electro neutrality can be written for the temperatures when the shallow donors are fully ionized and the upper energy level of radiation defects is ionized partially:

$$
N(L-1)+n_{a}+n=N_{d},
$$




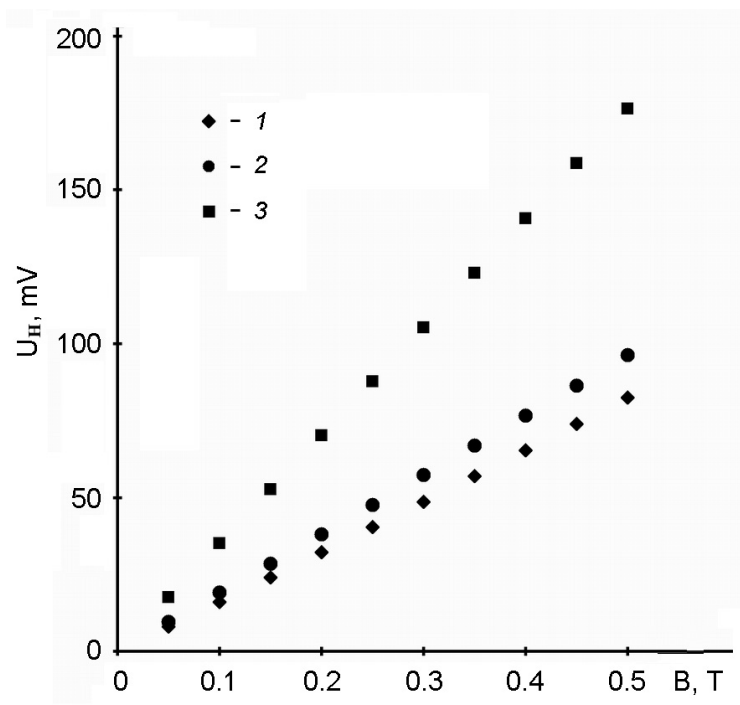

Fig. 5. Dependences of Hall voltage at $T=$ $300 \mathrm{~K}$ for the irradiated single crystals $n-\mathrm{Ge}$ after the isothermal annealing at $T_{a n}=$ $403 \mathrm{~K}$, for different times of annealing $t_{a n}$, h: $1-5 ; 2-1 ; 3-3$.

where $n_{e}$ is the concentration of electrons at the highest on a scale of energies acceptor level, $n$ is the concentration of electrons in the conduction band, $N_{d}$ is the concentration of the donor's impurity. Taking into account the expressions for corresponding concentrations [28]

$$
n_{a}=\frac{N}{2 e^{\frac{E_{a}-F}{k T}}+1}, \quad n=N_{c} e^{\frac{F}{k T}},
$$

the equation (5) can be written as follows:

$$
N(L-1)+\frac{N}{1+\frac{2 N_{c}}{n} e^{\frac{E_{a}}{k T}}}+n=N_{d}
$$

$N_{c}=\left(2 m_{n} k T\right)^{3 / 2} / 4 \pi^{3} \hbar^{3}$ is the effective density of states of the conductivity zone, $F$ is the Fermi energy. Three unknown parameters of radiation defects appear in the equation (7). These parameters could have been changed in comparison with the irradiated (non-annealed) samples: $N$ is the concentration of radiation defects, $L$ is the number of the acceptor levels that belong to each such defect, $E_{a}$ is the ionization energy of the highest on a scale of energies acceptor level. To calculate these parameters, we write the equation (7) for three different values of concentration of electrons. As a result, we obtain the following system of equations:

$$
\left\{\begin{array}{l}
N(L-1)+\frac{N}{1+\frac{2 N_{c}\left(T_{1}\right)}{n_{1}} e^{\frac{E_{a}}{k T}}}+n_{1}=N_{d}, \\
N(L-1)+\frac{N}{1+\frac{2 N_{c}\left(T_{2}\right)}{n_{2}} e^{\frac{E_{a}}{k T}}}+n_{2}=N_{d}, \\
N(L-1)+\frac{N}{1+\frac{2 N_{c}\left(T_{3}\right)}{n_{3}} e^{\frac{E_{a}}{h T}}}+n_{3}=N_{d}
\end{array} .\right.
$$

Experimental values of concentrations of electrons $n_{1}, n_{2}, n_{3}$, for the corresponding temperatures $T_{1}, T_{2}, T_{3}$, can be easily found out from the temperature dependences of Hall constant (curves 1-4, Fig. 3 and curves 2-3, Fig. 4). For the annealed samples $n-G e$ the radiation defects' parameters mentioned above have been calculated in different modes, considering the obtained experimental results, the value of the effective mass for a density of states for electrons of the germanium conduction band and concentration of the impurity $\mathrm{Sb} N_{d}=$ $5 \cdot 10^{14} \mathrm{~cm}^{-3}$. Parameters $L$ and $E_{a}$ were the same as for irradiated (non-annealed) $n-G e$ single crystals [17]. This fact indicates on impossibility or a small efficiency the formation of other types of radiation defects. Results of calculations of the radiation defects concentrations (A-centers) for the annealed samples are shown in Tables 1 and 2 . The calculations show that concentration of A-centers decreases at the temperatures of annealing $433 \mathrm{~K}$ and $448 \mathrm{~K}$ and increases at the temperature of annealing $403 \mathrm{~K}$ to $3 \mathrm{~h}$.

\section{Results and discussions}

The analysis of the obtained results shows that a heat treatment of $n-G e$ single crystals, irradiated by the high energy electrons, has a significant impact on their sensitivity to the magnetic field. The magnetic sensitivity of the $n-\mathrm{Ge}$ at the temperatures of annealing $T_{a n}=433 \mathrm{~K}$ and $T_{a n}=448 \mathrm{~K}$ decreases for the entire investigated range of temperatures, in comparison with the irradiated (non-annealed) samples. This effect may be explained by a decrease in the concentration of A-centers at annealing. The growth of the magnetic sensitivity for the entire investigated the range of temperatures is observed at a temperature of annealing $T_{a n}=403 \mathrm{~K}$ for annealing time up to $3 \mathrm{~h}$. Under such conditions of annealing 
Table 1. Concentrations of A-centers in the irradiated by electrons $n-G e$ after isothermal annealing over a period $t_{a n}=1 \mathrm{~h}$, at different annealing temperatures

\begin{tabular}{|c|c||}
\hline $\begin{array}{c}\text { Annealing temperature } \\
T_{a n}, \mathrm{~K}\end{array}$ & $\begin{array}{c}\text { Concentration } \\
\text { of A-centers } N, \mathrm{~cm}^{-3}\end{array}$ \\
\hline Unannealed sample & $2.8 \cdot 10^{14}$ \\
403 & $4.5 \cdot 10^{14}$ \\
433 & $2.1 \cdot 10^{14}$ \\
448 & $1.4 \cdot 10^{14}$ \\
\hline
\end{tabular}

Table 2. Concentrations of A-centers in the irradiated by electrons $n-G e$ after isothermal annealing at temperature $T_{a n}=403 \mathrm{~K}$ for different times of annealing $t_{a n}$

\begin{tabular}{|c|c||}
\hline $\begin{array}{c}\text { Time of } \\
\text { annealing } t_{a n}, \mathrm{~h}\end{array}$ & $\begin{array}{c}\text { Concentration of A-centers } \\
N, \mathrm{~cm}^{-3}\end{array}$ \\
\hline 1 & $4.5 \cdot 10^{14}$ \\
3 & $4.6 \cdot 10^{14}$ \\
5 & $4.4 \cdot 10^{14}$ \\
\hline
\end{tabular}

as it leads from the theoretical calculations (Table 2), the concentration of A-centers in the annealed samples increases in comparison with the irradiated (non-annealed) $n-G e$ single crystals. As we have explained previously [18], irradiation of the same samples $n-G e$ by a flow of electrons $\Omega=$ $5 \cdot 10^{15} \mathrm{el} . / \mathrm{cm}^{2}$, with the energy of $10 \mathrm{MeV}$, leads to the formation of A-centers and regions disordering. According to the Hosik model, the region disordering is a macroscopic inclusion of the spherical form with a large concentration of vacancies $\left(10^{18_{-}}\right.$ $10^{20} \mathrm{~cm}^{-3}$ ) in its kernel [29]. The gradient of the vacancies concentration between the kernel of region disordering and its shell causes the diffusion of vacancies into the conductive matrix of $n-G e$ single crystal. The vacancies, which had been created at the annealing of kernels of regions disordering, may again react with oxygen and interstitial atoms of germanium and form new A-centers correspondingly [26, 27].

Therefore, we can conclude that at heat treatment of the irradiated $n-G e$ single crystals the process of annealing occurs in parallel with the process of A-centers generation. Processes of the A-centers annealing prevail over on such of their creations at the temperatures of an isothermal annealing $T_{a n}=433 \mathrm{~K}$ and $T_{a n}=448 \mathrm{~K}$ within one hour.
Generation of the A-centers appears at a temperature of annealing $T_{a n}=403 \mathrm{~K}$, for times of annealing to $3 \mathrm{~h}$. An increase of the heat treatment time $\left(t_{a n}>3 \mathrm{~h}\right)$ at a temperature of $T_{a n}=403 \mathrm{~K}$ leads to the decrease of the magnetic sensitivity. This effect can be explained by the reduction of the regions disordering concentrations and vacancies correspondingly, from which can be formed A-centers.

\section{Conclusions}

Thus, the highest possible concentration of A-centers at a temperature of annealing $T_{a n}=403 \mathrm{~K}$ over a period of 3 hours is generated. This effect explains a significant increase of the magnetic sensitivity $n-G e$, the obtained at the room temperature unlike of the non-irradiated samples. One can see the growth from $\beta=10 \mathrm{mV} / \mathrm{T}$ to $\beta=$ $350 \mathrm{mV} / \mathrm{T}$ at a current $I=1 \mathrm{~mA}$ through the crystal and the Hall plate thickness in the direction of the magnetic field $d=$ $0.9 \mathrm{~mm}$. As far as the thickness of Hall detector in Hall's sensors is $0.2-0.3 \mathrm{~mm}$ as a rule, and current can vary from units to tens of milliamperes [6], then a change of the given parameters will allow increasing the magnetic sensitivity of the investigated samples tenfold.

That's why, $n-G e$, which had been irradiated by the high energy electrons and passed the heat treatment additionally, can be a perspective material for creation of the highly sensitive sensors of the magnetic field on its basis. A high threshold sensitivity (owing to the high magnetic sensitivity) and higher (in comparison with non-irradiated samples) resistance to the various types of radiation will be the primary advantages of such sensors.

\section{References}

1. Ch.Schott, P.-A.Besse, R.S.Popovic, Sensors and Actuators A: Physical, 85, 111 (2000).

2. A.Danilov, Modern Electron., 10, 26 (2004).

3. A.F.Aleinikov, V.A.Gridchin, M.P.Tsapenko, Sensors (Perspective Directions of Development), NSTU Publishing House, Novosibirsk (2001) [in Russian].

4. A.F.Kaperko, Meas. Techn., 1, 3 (1998).

5. Y.H.Kahng, Y.W.Kim, M.S.Kim et al., J. Korean Phys. Soc., 69, 1456 (2016).

6. V.A.Antropov, L.Kh.Antropova, Application of Galvanomagnetic Phenomena in Semiconductors for the Development of Microwave Devices, PGU, Penza (2011) [in Russian].

7. I.Duran, O.Hronova, J.Stockel et al., Rev.Sci. Instrum., 79, 10F123 (2008). 
8. J.Yang, J.W.Lee, B.K.Jung et al., Rev.Sci. Instrum., 85, $11 \mathrm{D} 809$ (2014).

9. J.A.Tapia, A.L.Herrera-May, P.J.GarcaRamrez et al., Biomed Microdevices, 13, 303 (2011).

10. J.Lenz, S.Edelstein, IEEE Sensors J., 6, 631 (2006).

11. S.Tumanski, Przeglad Elektrotechniczny, 10, 1 (2013).

12. I.Bichurin, V.Petrov, R.V.Petrov et al., Ferroelectrics, 280, 199 (2002)

13. V.S Osadchuk, O.V.Osadchuk, O.P.Bililivska, O.M.Zhaglovskaya, Bull. NTU "KhPI", 42, 948 (2012).

14. K.Staroverov, Integral Hall Sensors of the "Honeywell". Electron. News, 1, 9 (2010).

15. S.Sysoeva, Components and Technology, 1, 19 (2012).

16. N.T.Gorbachuk, P.I.Didenko, Surface, 4, 57 (2005).

17. S.V.Luniov, A.I.Zimych, P.F.Nazarchuk et al., Nucl. Phys. Atomic Energy, 17, 47 (2016).

18. S.Luniov, A.Zimych, P.Nazarchukc et al., $J$. Phys. Studies, 19, 4704 (2015).

19. J.Fage-Pedersen, A.N.Larsen, A.Mesli, Phys. Rev.B., 62, 10116 (2000).
20. A.P.Dolgolenko, Nucl. Phys. Atomic Energy, 14, 377 (2013).

21. E.V.Kuchis, Galvanomagnetic Effects and Methods of their Investigation, Radio and Communication, Moscow (1990) [in Russian].

22. V.I.Smirnov, Non-destructive Methods for Controlling the Parameters of Semiconductor Materials and Structures, UISTU, Ulyanovsk, (2012) [in Russian].

23. O.I.Podkopaev, T.V.Kulakovskaya, A.F.Shimanskii, N.O.Molotkovskaya, Phys. Solid State, 55, 949 (2013).

24. V.M.Babich, P.I.Baranskii, V.A.Shershel, Phys. Stat. Solidi, 42, K23 (1970).

25. G.P.Gaidar, V.A.Girii, V.I.Shakhovtsov, Phys. Techn. Semicond., 20, 2109 (1986).

26. Ya.M.Olikh, I.A.Lisyuk, N.D.Timochko, Techn. Design Electron. Equip., 3, 9 (2004).

27. E.N.Vologdin, A.P.Lysenko, Integral Radiation Changes of the Parameters of Semiconductor Materials, MGIEM, Moscow (1998) [in Russian].

28. P.S.Kireev, Physics of Semiconductors, Vysshaya Shkola, Moscow (1969) [in Russian].

29. B.R.Gossik, J.Appl.Phys., 30, 1214 (1959). 